\title{
NA BUSCA PELA IMPRESSÃO DIGITAL DOS CURSOS DE DIREITO NO BRASIL: DE COIMBRA A OLINDA (RECIFE) E SÃO PAULO
}

\author{
In the search for the digital printing of Courses of Law in Brazil: \\ From Coimbra to Olinda (Recife) and São Paulo
}

\begin{abstract}
En busca por la impresión digital de los cursos de Derecho en Brasil: de Coimbra la
\end{abstract} Olinda (Recife) y São Paulo

João Virgílio Tagliavini ${ }^{1}$

Plínio Gentil ${ }^{2}$

\section{Resumo}

Este trabalho, fruto de pesquisas autônomas dos autores, e, sobretudo, do estágio de pós-doutorado de TAGLIAVINI na Faculdade de Direito de Recife e de Coimbra, procurou e procura estabelecer um perfil do que seria a impressão digital, o verdadeiro e primeiro traço identificador dos cursos de Direito no Brasil, objetivando compreender a atual realidade de ensino. O texto mostra a influência coimbrã que, por meio da filosofia escolástica difundida na educação durante tempos pelos jesuítas, produziu um ensino do direito abstrato e essencialista, distante da realidade histórica e material. Pela ausência de formação específica para a docência, aponta-se como hipótese que os professores dos cursos de Direito no Brasil reproduziram, por imitação, um modelo de ensino transplantado de Coimbra para Olinda e São Paulo.

PALAVRAS-CHAVE: Educação jurídica no Brasil. Faculdade de Direito de Recife. Faculdade de Direito de Coimbra. Impressão digital. Influência jesuítica.

\begin{abstract}
This work, the result of autonomous research by the authors, and especially of the post-doctoral stage of TAGLIAVINI at the Faculty of Law of Recife and Coimbra, sought and sought to establish a profile of what would be the digital impression, the true and first trait identifier of law courses in Brazil, aiming to understand the current reality of teaching. The text shows the Coimbra influence that, through the scholastic philosophy spread in education during times by the Jesuits, produced a teaching of abstract and essentialist law, far from historical and material reality. Due to the absence of specific training for teaching, it is hypothesized that the teachers of law courses in Brazil reproduced, by imitation, a transplanted teaching model from Coimbra to Olinda and São Paulo.
\end{abstract}

\footnotetext{
${ }^{1}$ Doutor em Educação (UFSCar), mestre em Sociologia (UNICAMP), graduado em Teologia, licenciado em Filosofia. Docente da graduação e pós-graduação em Educação (UFSCar). Líder do Grupo de Pesquisa Educação e Direito (UFSCar). Pesquisador e autor de obras sobre educação jurídica. Contato: $<$ joaofederal@gmail.com>.

${ }^{2}$ Doutor em Direito (PUC-SP) e em Fundamentos da Educação (UFSCar). Professor universitário de Direitos Humanos (PUC-SP) e Direito Penal (UNIP-SJR.Preto). Procurador de Justiça no Estado de S. Paulo. Membro pesquisador do Grupo de Pesquisa Educação e Direito (UFSCar). Contato: 〈pabgentil@ pucsp.br>.
} 
KEYWORDS: Law education in Brazil. Recife Faculty of Law. Coimbra Faculty of Law. Digital impression. Jesuit influence.

\section{Resumen}

Este trabajo, fruto de investigaciones autónomas de los autores, y sobre todo de la etapa de postdoctorado de TAGLIAVINI en la Facultad de Derecho de Recife y de Coimbra, buscó y busca establecer un perfil de lo que sería la huella digital, el verdadero y primer rasgo identificador de los cursos de Derecho en Brasil, con el objetivo de comprender la actual realidad de enseñanza. El texto muestra la influencia coimbra que, por medio de la filosofía escogida difundida en la educación durante tiempos por los jesuitas, produjo una enseñanza del derecho abstracto y esencialista, distante de la realidad histórica y material. Por la ausencia de formación específica para la docencia, se apunta como hipótesis que los profesores de los cursos de Derecho en Brasil reprodujeron, por imitación, un modelo de enseñanza transplantada de Coimbra para Olinda y São Paulo.

PALABRAS CLAVE: Educación jurídica en Brasil. Universidad de Buenos Aires. Universidad de Buenos Aires. Impresión digital. Influencia jesuítica.

\section{INTRODUÇÃO}

Estabelecer um perfil da impressão digital ${ }^{3}$ dos cursos de Direito no Brasil é uma proposta que surge da necessidade de compreender a crise endêmica do ensino jurídico e, consequentemente, a baixa produtividade dos mais de 1250 cursos de Direito existentes atualmente no país.

Para tanto é preciso estudar as origens da educação jurídica no Brasil até chegar à sua nascente, sua fonte primeira. Já se sabe que os primeiros cursos de Direito, os de São Paulo e Olinda, brotaram onde funcionavam instituições religiosas: mosteiros e conventos. Mas era preciso ir além e foi assim que um dos autores (TAGLIAVINI), em seu estágio de Pósdoutorado, decidiu-se por uma permanência em Coimbra - pois ali parecia estar a matriz geradora dos cursos de São Paulo e de Olinda -, com uma passagem por Évora - e outra em Recife, locais onde também esteve GENTIL, para pesquisas não documentadas. Importante lembrar que foi em Coimbra, na sua tão tradicional universidade, que se formou quase a totalidade das elites brasileiras durante o período colonial.

Nesse texto, os autores apresentam, na primeira parte, um contexto histórico dos cursos de direito no Brasil, desde suas origens, até a atualidade, mostrando a evolução do

\footnotetext{
${ }^{3}$ Com o uso desta expressão buscam os autores frisar que o objetivo é estabelecer, até onde possível, o padrão identitário dos cursos de Direito, aquilo que, conhecidas suas fontes primeiras, os identifica dentre outros.
} 
número de cursos e de matrículas, a metodologia e a epistemologia, enfim, tudo o que conduz à pergunta sobre os fatores que levaram à atual situação.

Na segunda parte, são apresentadas as buscas, entre Olinda, Recife e Coimbra, na pelos traços identificadores dos cursos de Direito no Brasil. O texto vem acompanhado de algumas imagens: a arte é também fonte de educação e, não raras vezes, chave para sua compreensão. A observação da arquitetura muito auxilia no entendimento de uma epistemologia voltada sobre si mesma, protegida pelas grossas paredes do claustro, metafísica, e, portanto, desligada do mundo. Além disso, observou-se em Recife que poucos conhecem a história de sua faculdade nesses detalhes.

Na terceira parte estão as "primeiras colheitas" da pesquisa. São primícias e temas a serem trabalhados com a profundidade que merecem, e, para isso, foi colhido material nas ricas bibliotecas de Recife e Coimbra, além de outras obras importantes, adquiridas em sebos, nessas cidades. Como resultados importantes desta pesquisa, destacam-se quatro descobertas: o direito nasceu e continua dentro dos claustros; Pombal expulsou os jesuítas, mas o jesuitismo triunfou; no Brasil, tudo se resolveu pela conciliação - entre as elites e contra o povo; Olinda se propôs a ser a Coimbra brasileira.

A pesquisa segue o método indutivo e é principalmente bibliográfica, mas também de campo.

\section{As origens: o contexto histórico da criação dos cursos de Direito}

Nossos primeiros cursos de Direito foram criados por lei assinada pelo imperador Pedro I, aos 11 de agosto de 1827, para formar as elites dirigentes brasileiras, em substituição à formação até então recebida em Coimbra. Nasciam, assim, as Faculdades de Direito de Olinda e São Paulo. Posteriormente, em 1854, a de Olinda foi transferida para Recife. Essas faculdades não nasceram Universidades, mas cursos isolados e não com a preocupação primeira em formar bons juristas em direito pátrio, mas em formar dirigentes para um país que nascia, em um direito transplantado ${ }^{4}$.

É preciso colocar o direito dentro da questão educacional brasileira mais ampla. Vejamos a preocupação tardia com a implantação de uma universidade no Brasil.

\footnotetext{
${ }^{4}$ Apesar da proclamação da independência, continuaram em vigor no Brasil as Ordenações Filipinas, que foram, aos poucos, sendo substituídas pelo direito pátrio, que conheceu uma primeira codificação em Teixeira de Freitas (iniciou os estudos de direito em Olinda, continuou-os em São Paulo e concluiu em Olinda). O primeiro código civil brasileiro só será aprovado em 1916, com o Projeto de Clóvis Beviláqua, aluno e professor do Curso de Direito de Olinda/Recife.
} 
Na Europa, a primeira universidade foi fundada em Bolonha, em 1088; e a segunda, em Paris, em 1125. Na América, os espanhóis criaram a primeira universidade em Santo Domingo, em 1538; em 1551 foram criadas as universidades no México e em Lima; em 1580, em Bogotá; em 1586, no Equador; em 1597, no Peru. Enquanto isso, para se constatar o nosso atraso, o Brasil, que havia optado, a partir da vinda da família real, em 1808, pela criação de cursos superiores isolados, só conheceu sua primeira experiência universitária no século XX, com algumas iniciativas, na década de 1920, no Rio de Janeiro e Minas Gerais e, com a bem sucedida criação da Universidade de São Paulo (USP), em 1934. É uma universidade temporã, na expressão de Luiz Antônio Cunha (CUNHA: 1986). Esse quadro mostra, portanto, a disparidade entre o período de implantação das universidades nos territórios de colonização espanhola e de colonização portuguesa.

Em uma palestra, em comemoração aos setenta anos da criação da UFPE, no dia 11 de agosto de 2016, no salão nobre da Faculdade de Direito de Recife, o reitor da Universidade de Coimbra, João Gabriel Monteiro de Carvalho e Silva, defendeu a tese de que o território brasileiro não se fragmentou após a independência, porque todas as suas elites eram formadas na mesma instituição, em Coimbra, onde o governo português controlava as ideias, diferentemente das colônias espanholas que tiveram universidades desde o século XVI e, por isso, suas elites fragmentaram o território, após a independência, formando países diferentes.

Obviamente, do ponto de vista brasileiro, isso atrasou em demasia o processo educacional, pois, somente no século XIX, o Brasil se preocupa com uma educação básica pública, e, mesmo assim, para formar partes de suas elites, estando mais preocupadas com a distinção social que as letras e os diplomas conferiam aos seus nobres decadentes e à burguesia nascente, do que com a produção de riquezas para todo o país.

O resultado de todo esse descaso pela educação é que o Brasil ingressa no século XX com quase $90 \%$ de analfabetos, já que um país monocultor, agrário, exportador, escravocrata, não precisava de escolas.

É no século XX que o Brasil fará o esforço de organizar sua rede de ensino, criando o Ministério da Educação, o Conselho Nacional de Educação, canalizando investimentos para a universalização do ensino fundamental e, posteriormente, do ensino médio. Mas foi uma democratização do ensino que, no seu primeiro momento, não teve preocupação com a qualidade, oferecendo, sim, escolas para todos ou quase todos, de baixa qualidade, 
incentivando o crescimento de enorme rede de ensino privado, pago, para os filhos da classe média e das elites.

Na década de 1960, com a pressão por vagas no ensino superior, o Brasil fez sua reforma do ensino, ampliando o espaço da iniciativa privada também nesse nível. E, assim, as portas do ensino superior abriram-se para muitos brasileiros que antes nem poderiam sonhar com um título universitário. Foi um período de grande expansão das matrículas, sem que a qualidade acompanhasse o crescimento. Depois de um pequeno adormecimento, na década de 1990, deu-se outra grande expansão. É nesse quadro que os cursos de Direito saltam de 165, em 1991, para 1121, no ano de 2011.

\section{Criação e expansão dos cursos de Direito no Brasil: quantidade e qualidade}

Ainda está longe de ser resolvido o impasse entre aqueles que acham que o ensino decaiu devido à quantidade e aqueles que defendem que mais educação se faz com mais escolas e não com menos escolas. Na verdade, quer parecer que em nenhum momento da história do Brasil, houve crise da educação por excesso de escolas ou excesso de educação.

Vejam-se os números para discuti-los a seguir. Primeiramente se colocam duas tabelas. A tabela 1 mostra um tempo lento de crescimento do número de cursos de Direito no Brasil, desde os dois primeiros cursos, em Olinda e São Paulo, até os 108 cursos, em 1970, após a primeira grande expansão:

Tabela 1

\begin{tabular}{|c|c|}
\hline \multicolumn{2}{|c|}{ CURSOS DE DIREITO NO BRASIL } \\
1827 - 1970 \\
\hline Ano & Número de cursos \\
\hline 1827 & $\mathbf{2}$ \\
\hline 1900 & $\mathbf{6}$ \\
\hline 1930 & 14 \\
\hline 1950 & $\mathbf{2 5}$ \\
\hline 1970 & 108 \\
\hline Fonte:MEC/INEP - Tabela elaborada por INEP/DEED
\end{tabular}


Tabela 2

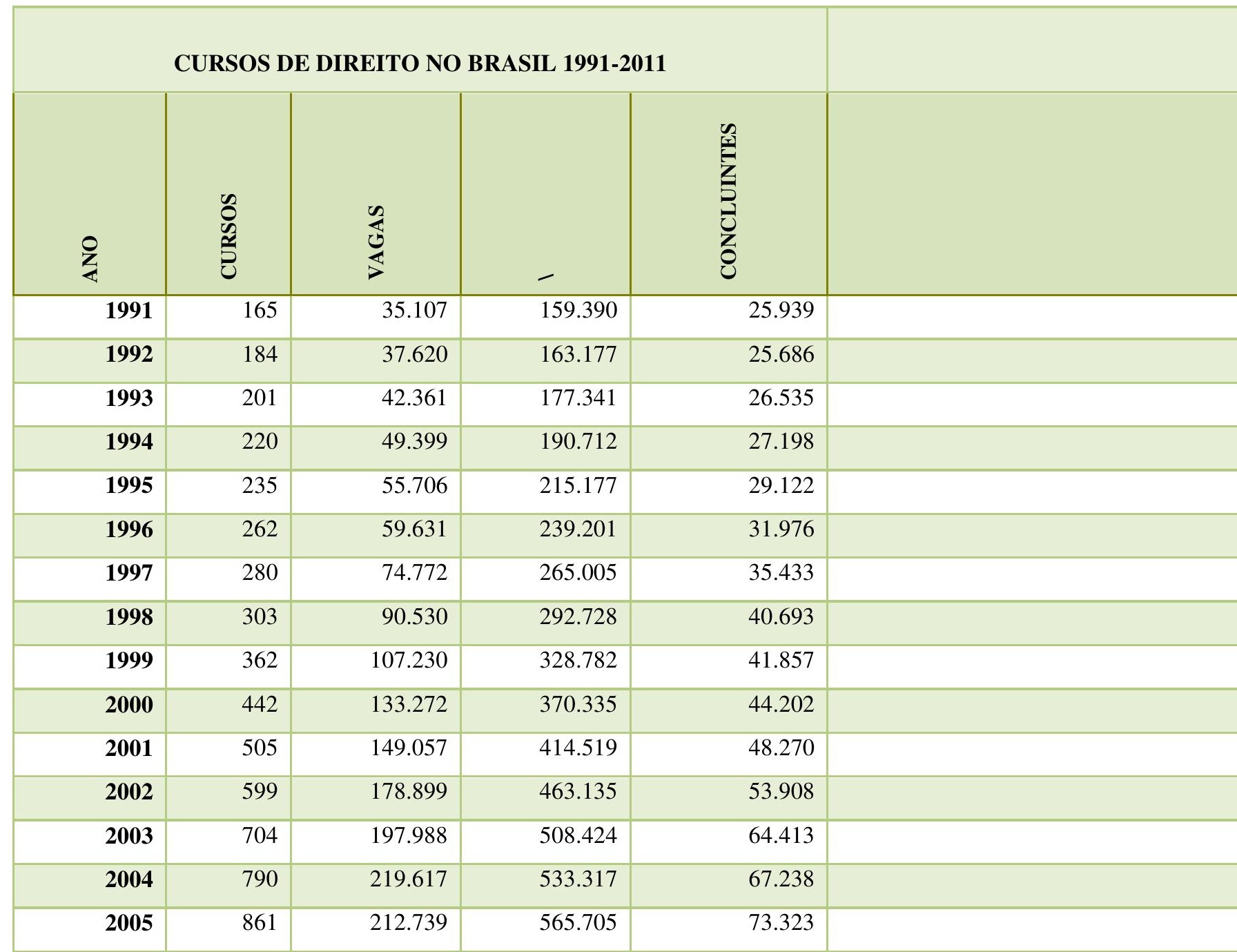




\begin{tabular}{|r|r|r|r|r|r|}
\hline $\mathbf{2 0 0 6}$ & 971 & 227.831 & 589.351 & 79.181 & \\
\hline $\mathbf{2 0 0 7}$ & 1.051 & 241.184 & 613.950 & 82.830 & \\
\hline $\mathbf{2 0 0 8}$ & 1.080 & 240.077 & 638.741 & 85.072 & \\
\hline $\mathbf{2 0 0 3}$ & 1.097 & 224.432 & 651.730 & 87.523 & \\
\hline $\mathbf{2 0 1 0}$ & 1.092 & 218.752 & 694.545 & 91.035 & \\
\hline $\mathbf{2 0 1 1}$ & 1.121 & 214.821 & 723.044 & 95.008 & \\
\hline
\end{tabular}

\section{Fonte:MEC/INEP - Tabela elaborada por INEP/DEED}

A tabela 2 mostra um tempo de crescimento muito mais rápido, em que, durante a segunda grande expansão, em 20 anos, o número de cursos passa de 165 para 1121.

Em 2013, os cursos de Direito ofereceram mais de 250 mil vagas anuais, e são, em geral, noturnos, em faculdades e não em universidades, mantidas, em sua maioria, por instituições privadas, com pouquíssima seleção dos candidatos.

Depois do impeachment da presidente Dilma Rousseff, em 2016, a expansão do ensino superior deverá sofrer uma retração, ao que tudo indica, pois os primeiros sinais do governo que a substituiu apontam na direção da desoneração do Estado em relação às políticas públicas. Alguns políticos da base governista verbalizaram que "quem não tem dinheiro não tem que fazer universidade" 5 .

Embora não se deva considerar que os resultados dos exames da $\mathrm{OAB}$ sejam parâmetros para medir a qualidade dos cursos de Direito, a média de aprovação do I ao XIX Exame de Ordem Unificado, que foram aplicados de junho de 2010 a maio de 2016, é de apenas $18,78 \%$. Isso significa que $81,22 \%$ dos bacharéis que prestaram os exames foram reprovados, alguns deles diversas vezes. Como se trata de um exame baseado na navegação de cabotagem ao redor dos códigos, pode-se dizer que os cursos não têm tido sucesso nem na memorização do direito positivo.

\section{O centro e a margem: entre a tradição e a liberdade}

O que já foi monopólio de uma ou outra instituição que mantinha um curso de Direito, atraindo interessados de toda a região à sua volta, caiu no estado de concorrência.

\footnotetext{
${ }^{5}$ Consta como sendo afirmação do deputado federal Nelson Marquezelli, do PTB/SP, disponível em: <http://www.gazetadopovo.com.br/blogs/certas-palavras/quem-nao-tem-dinheiro-nao-faz-universidade-defendedeputado/>. Acesso em: 22 out. 2016.
} 
Veja-se, por exemplo, o que ocorria no centro geográfico do Estado de São Paulo, onde uma só faculdade, até o início da década de 1990, recebia alunos de uma área que hoje conta com, pelo menos, mais 20 cursos de Direito. Todavia, entre 1993 e 2013 foram implantados muitos cursos na região. Isso se refletiu, imediatamente, nos processos seletivos, que antes atraíam quase uma dezena de candidatos por vaga, e passaram a oferecer muitas vagas para um candidato. Isso pode acontecer com qualquer instituição que não acompanhar os rumos que a educação superior está tomando no país, nesse Estado pouco investidor, bastante avaliador, num mercado concorrencial. Quem continuar deitado eternamente em berço esplêndido verá, inevitavelmente, que um filho seu abraçará a morte.

Para aqueles que argumentam que a comparação entre instituições historicamente muito diferentes é injusta, vale lembrar que o atual modelo do ENADE corrige, em parte, as distorções e que, se uma faculdade antiga ganha em tradição, uma instituição nova ganha em liberdade e possibilidade de criatividade. A Faculdade de Direito da Universidade de São Paulo, no Largo São Francisco, ou a Faculdade de Direito de Recife, antiga faculdade de Olinda, ganham em TRADIÇÃ ${ }^{6}$; os cursos novos ganham em LIBERDADE. A tradição é boa, mas também pesa. A tradição dos cursos de Direito vindos de Coimbra somou-se a duas outras tradições: ao Império e à Igreja, afinal uma faculdade nascia no Mosteiro de São Bento de Olinda e outra no Convento de São Francisco, em São Paulo - ambas nas sombras de igrejas em estilo colonial. E a tradição continua ${ }^{7}$ em departamentos, centros, congregações, engessamento do currículo, ementas que podem ficar defasadas, professores desestimulados para trabalharem com a graduação e outras amarras do serviço público ${ }^{8}$. Em situação como essa, fica mais difícil acompanhar a dinâmica do direito dos dias atuais. As instituições que ainda estão no berço têm o privilégio da liberdade para acompanhar as rápidas transformações da sociedade e do direito, embora possam perder, por exemplo, na riqueza de uma biblioteca histórica do direito ou na titulação de seus docentes. Em todo caso, a concorrência é desleal, sendo ambas julgadas por idêntico instrumento de avaliação. Uma eventual nota "3" que, porventura, venha a ser atribuída a uma instituição nova dos confins do Brasil, significará,

\footnotetext{
${ }^{6}$ Tomem-se como exemplo essas duas universidades por serem as mais antigas do Brasil; mas se poderia falar de qualquer universidade antiga do mundo. E também não se faz qualquer juízo de valor em relação ao trabalho que colegas professores desenvolvem lá.

${ }^{7}$ Em 1854 a faculdade de Olinda é transferida para Recife; na década de 1930 o antigo convento de São Francisco dá lugar ao novo prédio da Faculdade de Direito da USP, que continua ao lado da igreja e do convento de São Francisco.

${ }^{8}$ Isso tudo pode ser bem conhecido nos depoimentos publicados em livro de Ana Luiza Martins e Heloisa Barbuy, intitulado As arcadas, editado pela Melhoramentos/Alternativa.
} 
relativamente, em termos de esforço de seu coordenador, do trabalho de seus docentes e do desempenho de seus bacharelandos muito mais do que um " 5 " atribuído a uma das grandes tradicionais, ou de instituições mais novas implantadas em grandes centros, destinadas às elites com poder de bancar suas mensalidades ${ }^{9}$. Portanto, é preciso saber ler os resultados das avaliações com perspectiva histórica e geográfica, com visão de totalidade.

O privilégio da liberdade, por sua vez, não significa que todos aqueles que a têm saberão direcioná-la, no sentido de manter a sintonia do curso com as exigências e transformações do direito. Poderão ser feitas experiências infrutíferas ou até desastrosas. Talvez, por isso, a maioria prefira o caminho tradicional, mesmo que não esteja produzindo excelentes frutos, ou quase fruto algum. Para abraçar o privilégio da liberdade é preciso a segurança de estar bem fundamentado em suportes teóricos e metodológicos sólidos. Só quem tem muita segurança abraça o caos, superando a monotonia e ineficiência do cosmos, da ordem, e vai em frente, produzindo o novo. Para isso é necessário muito investimento, principalmente em formação docente.

\section{Direito que se aprende direito: a ousadia do novo}

Está posta uma parte do diagnóstico e estão postos os desafios. Agora, resta perguntar: qual a proposta para que sejam colocadas as reais condições para uma eficaz aprendizagem do direito?

Todos aqueles que buscam resultados práticos costumam procurar receitas de curto prazo. No caso do ensino não há receitas nem há curto prazo. Há uma mudança de postura e de processo de ensino e aprendizagem. Há a coragem de questionamento dos paradigmas positivistas do direito que se ensina errado para se mudar para o direito que se aprende certo.

\section{A epistemologia condiciona a metodologia que circunscreve as práticas}

didáticas. O paradigma dogmático positivista do direito gera um método de ensino que pode servir para alguns momentos, mas ao qual não pode ser reduzido todo o ensino. Alguns confundem a abordagem tradicional do ensino com a aula expositiva clássica. A aula é apenas um momento do método. A abordagem implica uma visão de mundo, de ensino, de aluno, de

\footnotetext{
${ }^{9}$ Quando se vê o selo "OAB RECOMENDA" um uma dessas IES, definitivamente se percebe que há uma tentativa em comparar grandezas incomparáveis. No passado quem recebia as "comendas" eram sempre os coronéis...
} 
professor, de conhecimento, de aprendizagem e de escola. Para a abordagem tradicional ${ }^{10}$, em sentido pejorativo, existe um professor, aquele que sabe, a transmitir um conhecimento único a um aluno, aquele que não sabe. O professor é o detentor do saber e não pode ser questionado. Nesse caso, o ensino se confundiria com transmissão de uma verdade dogmática, em uma aula expositiva.

A travessia do mar Vermelho, rumo à terra prometida do direito que se aprende direito, não se fará a pé enxuto, como Moisés. Se não se romper com o paradigma dogmático positivista tradicional, não haverá vitória na luta pela aprendizagem do direito. A mudança começa com um estudo sério e aprofundado sobre a melhor forma de aprender de maneira significativa. E isso se faz por meio de um diálogo com os maiores interessados: os estudantes. Esta é, portanto, a primeira postura da nova atitude: muito diálogo.

É preciso dizer, de passagem, para aqueles que, com razão, se preocupam com a necessidade da aprendizagem do direito positivo (somente baseado nos códigos), que o próprio direito, no sentido legalista-positivista, será mais bem aprendido, na medida em que o dogmatismo for superado, em que as disciplinas não forem tratadas de forma estanque, mas de forma orgânica, durante todo o curso, interpenetrando-se, fecundando-se. História, filosofia, sociologia, economia, psicologia e outras ciências humanas fecundam a compreensão e o aprendizado das leis por lhes darem sentido muito mais abrangente e profundo. A inter e a transdisciplinaridade, realizadas na prática, seriam a salvação de um direito sem gosto, nem sentido. A motivação poderá estar nesse diálogo fecundo entre os saberes que despertarão sabores. Um legalismo autorreferencial é circular e não faz sentido. Como diz o caboclo: é uma ciência que fica rodeando o toco.

\section{O que fazer diante de uma crise que sempre existiu?}

Olhando para o ingresso, para o processo ou para os resultados, o ensino do direito sempre esteve em crise. Isso ocorreu ou porque o ensino era para pouquíssimos e a exclusão

\footnotetext{
${ }^{10}$ A palavra tradição vem do verbo latino tradere que significa tanto trazer quanto levar. Tradição significa, portanto, trazer do passado para o presente e levar para o futuro a cultura, a história, os costumes e todos os conhecimentos de um povo. Então, é coisa boa. Pode-se falar também em uma abordagem conservadora. Mas isso não é necessariamente ruim, porque há muitas coisas boas que precisam ser conservadas, como os alimentos em nossas geladeiras, por exemplo. Seria melhor dizer ensino e aprendizagem bons ou ruins.
} 
era muito grande por critérios econômicos e até racistas ${ }^{11}$; ou porque os conteúdos eram inadequados ou impróprios e a metodologia autoritária; ou porque os resultados são desastrosos.

Diante dessa situação, há os que agem como avestruzes e não querem ver nada; há os que lamentam e acham impossível erguer a bandeira de qualquer renovação; há também os que se lançam em aventuras quixotescas sem fundamentos e sem estratégias bem definidas. Nenhum desses grupos estará colaborando pela mudança de situação.

O que fazer? É a pergunta inevitável de todos aqueles que se sentem incomodados. E, como respostas, têm-se desde receitas prontas, com algumas soluções simplistas oferecidas como panaceias para todos os males, até uma chamada mais profunda à reflexão, ao debate prudente, mas, ao mesmo tempo, aberto, ousado e corajoso, na busca de saídas fecundas. Para que isso aconteça, é preciso superar a inércia dos satisfeitos e a ditadura dos bem sucedidos. Diante desse quadro, parece haver dois tipos de indivíduos: aqueles que dizem ser possível, mas muito difícil e aqueles que dizem ser muito difícil, mas possível. Uns apenas se espantam e perguntam por quê? Outros indagam por que não? Estes últimos fazem a história.

\section{A pesquisa: em busca da impressão digital dos cursos de Direito no Brasil}

Colocados os pressupostos históricos e metodológicos, ou o status quaestionis, a pesquisa, que muito se valeu das informações obtidas na Faculdade de Direito de Recife, teve por objetivo estudar os fundamentos teórico-metodológicos para identificar as mudanças e as sobrevivências do método "coimbrão" nos cerca de mil e duzentos cursos de Direito no Brasil atual e sua possível determinação na formação dos juristas. Sempre se considerou, como já dito, que, para compreender o atual estado da educação jurídica, seria necessário voltar ao passado e decifrar o sequenciamento do seu perfil, como uma cadeia de DNA. E isso levava a Olinda e a Coimbra, vista a já suficiente apreensão de informações acerca da história do curso de Direito de São Paulo.

E, de fato, no segundo semestre de 2015 TAGLIAVINI fez dois estágios de estudos e pesquisas na Faculdade de Direito de Recife (UFPE), o primeiro de um mês e o segundo de

\footnotetext{
${ }^{11}$ É importante lembrar que Luís Gama foi impedido de estudar no curso de Direito do Largo São Francisco, em São Paulo.
} 
quarenta dias. Tratou-se de um estágio fecundo de pesquisas, principalmente na Seção de Obras Raras da Biblioteca do Centro de Ciências Jurídicas da faculdade, um riquíssimo acervo para a reconstrução da trajetória histórica e das ideias da faculdade que se iniciou em Olinda, em 1828, e transferiu-se para Recife, em 1854. A pesquisa prosseguiu por meio de visitas ao mosteiro de São Bento, em Olinda, o centro de Olinda e do Recife antigos, que foram o ambiente onde nasceu e vicejou o curso de Direito.

Os estudos do segundo semestre de 2015, em Recife, confirmaram a tese inicial do projeto: para conhecer a nascente dos cursos de Direito no Brasil seria necessário pesquisar sua origem comum na Universidade de Coimbra. Assim, por quarenta dias, gastos entre Coimbra e Évora, no primeiro semestre de 2016, aconteceu outra rodada de pesquisas e entrevistas sobre aquele curso de Direito, fundado em 1290, de onde vieram, em 1828, os primeiros professores para lecionar e os primeiros alunos para concluir o curso de Direito em Olinda e São Paulo.

A estadia em Recife propiciou, além de tudo, uma preciosa coleta de material para leituras e análises posteriores. O conhecimento da história, da geografia, da arquitetura, das artes, enfim, do meio onde se implantou e se desenvolveu o curso de direito de Olinda que, depois se transferiu para lá, permitiu ir além da pesquisa bibliográfica e compreender o direito na cultura de um povo que teve intérpretes como Gilberto Freire e Joaquim Nabuco, a liderança de Hélder Câmara e, no direito, gerações de homens célebres que merecem ser estudados, principalmente a partir da obra de Gláucio Veiga, História das Ideias da Faculdade de Direito de Recife. Destacam-se Pontes de Miranda, Tobias Barreto, que ali estudou e foi mestre, Rui Barbosa e Castro Alves, que tiveram lá parte de sua formação acadêmica, e Clóvis Beviláqua (BEVILÁQUA: 1977), acadêmico e mestre, autor de uma obra que auxiliou bastante na interpretação dos primeiros tempos da Faculdade: História da Faculdade de Direito do Recife, que ele publicou em 1927, para comemorar o $1^{\circ}$ centenário do Curso de Direito.

\section{Arquitetura e ensino do Direito}

Um dos eixos da pesquisa de campo, em Olinda e Recife, foi o reconhecimento dos espaços por onde o curso passou, e foi oferecido, ao longo de quase dois séculos de existência, pois a arquitetura diz muito sobre o ensino, sua metodologia e sua epistemologia. 
A Faculdade de Direito de Recife ocupa hoje um majestoso prédio - que é a sua quinta morada. O curso criado por lei assinada por D. Pedro I, aos 11 de agosto de 1827, iniciou-se, efetivamente, com aulas, no dia 15 de maio de 1828, nas salas adaptadas do primeiro andar do mosteiro de São Bento de Olinda, o que se tornou um grande incômodo para os monges.

Fachada do Mosteiro de São Bento e Claustro (Olinda)

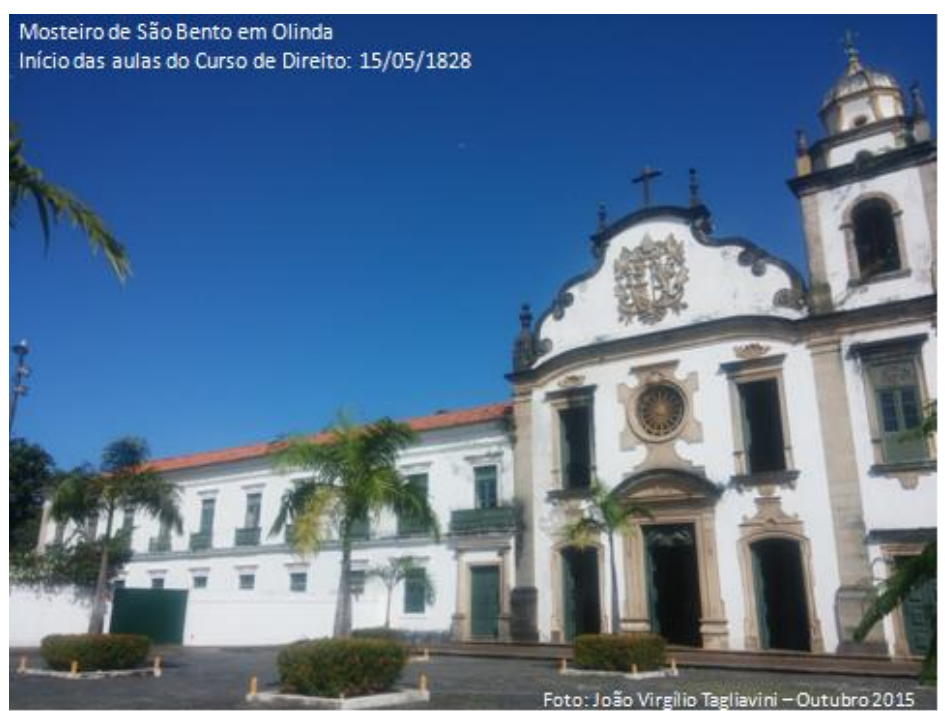

Fonte: Fotos de autor - 2015.

\section{Claustro Mosteiro São Bento de Olinda}

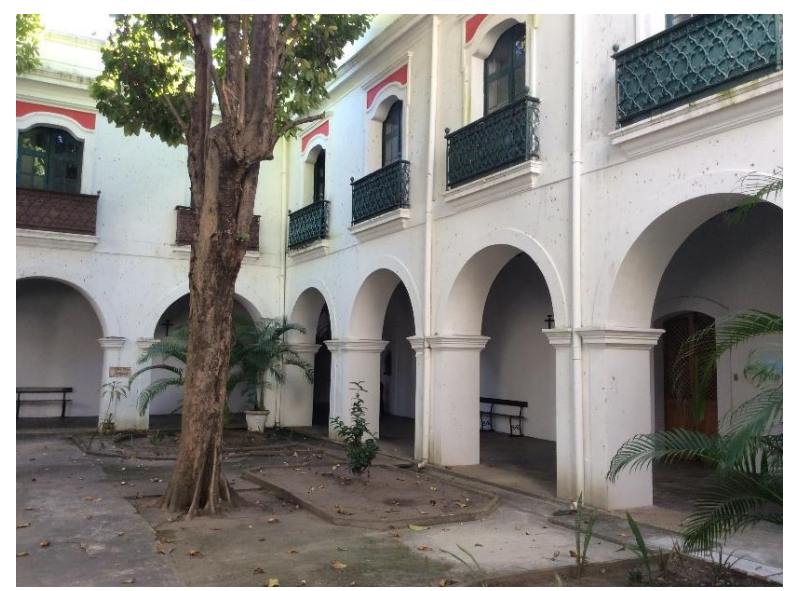

Fonte: Foto de autor: 11 agosto 2017 - 190 anos cursos de Direito no Brasil

A provisoriedade do local durou até 1852, quando, em 26 de agosto, o curso apenas subiu um pouco a ladeira da Rua São Bento e hospedou-se no antigo Palácio dos 
Governadores da Província e atual sede do executivo municipal de Olinda, espaço que ficou conhecido como "Academia".

Ali permaneceu apenas até 1854, quando, em 13 de novembro, transferiu-se para um antigo casarão, de muitos cômodos, na Rua do Hospício. Esse espaço também seria provisório porque era tão ruim que fora apelidado de "O Pardieiro". Mas aí o curso permaneceria até 1882. Joaquim Nabuco, Rui Barbosa, Castro Alves, Tobias Barreto, Silvio Romero e outros grandes intelectuais estudaram no Pardieiro. O casarão foi demolido e há contradições nas informações sobre o seu local preciso.

Não havendo mais condições de permanecer naquele casarão, foi só em julho de 1882 que o curso transferiu-se para um antigo colégio dos jesuítas, o Colégio de Jesus, na antiga Praça Pedro II, hoje Praça Dezessete. O prédio, que foi demolido em 1933 para a continuação da atual Rua do Imperador, era contíguo à atual igreja do Divino Espírito Santo, como mostra a foto abaixo. Também era muito incômodo, acanhado, sem ventilação; era provisório e durou até fins de 1911, quando ficou pronto o prédio atual.

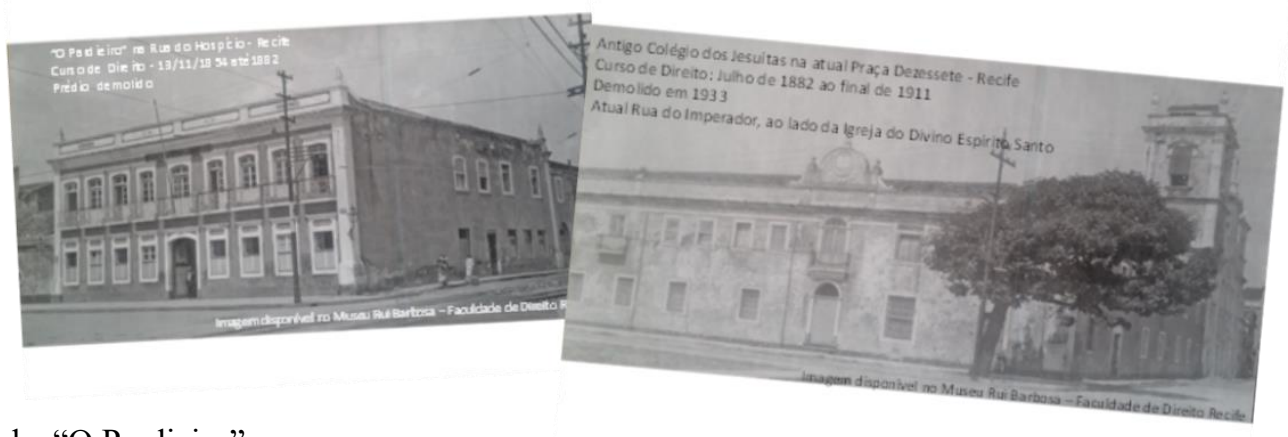

À esquerda, "O Pardieiro"

e, à direita, o "Colégio de Jesus"

Foi nesse prédio que Tobias Barreto exerceu a docência e expandiu a "Escola do Recife". O Pardieiro e o Colégio foram as verdadeiras “Casas de Tobias".

Faculdade de Direito de Recife, prédio inaugurado em 1912

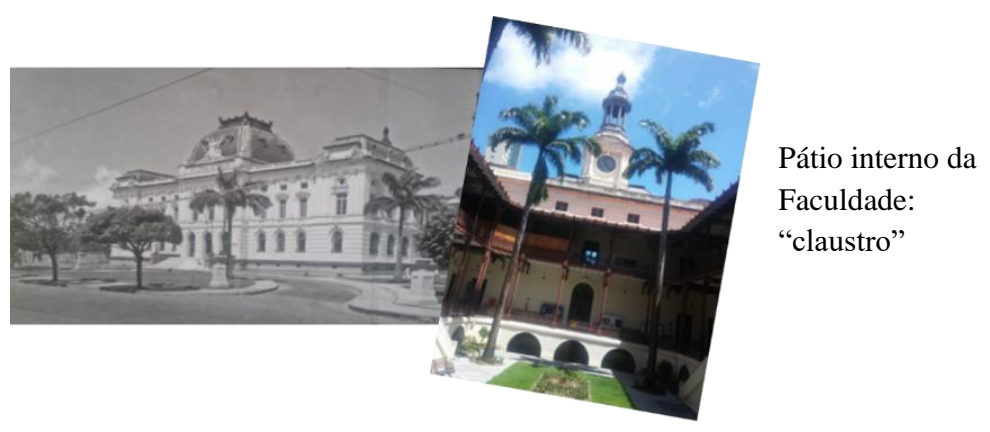




\section{Estágio em Coimbra}

A pesquisa de Pós-doutorado de TAGLIAVINI na Faculdade de Direito de Coimbra, no primeiro semestre de 2016, sob a supervisão da professora Dra. Ana Raquel Moniz, foi proveitosa, sobretudo por conta de três entrevistas com o seu diretor, professor Rui de Figueiredo Marcos, coautor de História do direito brasileiro (MARCOS: 2015), sócio do Instituto Histórico e Geográfico de São Paulo e membro do Instituto de Direito Comparado Luso-Brasileiro. Sua proximidade com o tema e a gentileza na acolhida facilitaram muito a pesquisa, e, na troca de ideias, muito se pôde avançar na direção das hipóteses iniciais do projeto.

Na biblioteca da Faculdade de Direito da Universidade de Coimbra, como não poderia deixar de ser, foi encontrado material muito rico para os objetivos da pesquisa. $\mathrm{O}$ acesso foi bastante facilitado, desburocratizado, podendo-se retirar livros. Outras obras puderam ser encontradas também na biblioteca central da universidade.

Uma visita guiada aos espaços mais históricos da universidade possibilitou contato e alguma experiência das tradições transplantadas para o Brasil por ocasião da criação dos cursos de Direito, em 1827. Desde sua arquitetura, em forma de claustro, um rico salão nobre, salas de aula no modelo escolástico, as vestes das cerimônias para os exames e formaturas, as tradições dos estudantes, tudo permitiu perceber o ambiente onde foram formadas as mudas dos cursos de Direito, depois levadas para o Brasil. E, além das tradições, nos primeiros anos foram mudados para o Brasil professores e alunos, que aqui vieram concluir os seus cursos.

\section{As Colheitas da Pesquisa}

\section{O ensino do Direito nasceu enclausurado}

Em Coimbra, Olinda, Recife e São Paulo, os cursos de Direito nasceram nos claustros. Não é de admirar. A Igreja se estabelece no Brasil, como instituição educadora, desde a primeira leva de jesuítas que aportaram com Tomé de Souza, em 1549. O jesuíta era vocacionado para ensinar. A demonstrar essa vocação, o púlpito da igreja emerge como peça fundamental do espaço sagrado. Conforme observado por MORAES (1979, p. 28), 


\begin{abstract}
As igrejas jesuíticas, ao contrário do goticismo dominante, não têm as naves obstruídas por um bosque de colunas, que prejudica a visualização do auditório. O púlpito é a peça essencial e o transeto sem profundidade [...]. É a igreja comicial. Domina-a [...] a mística, a palavra. É o verbo, o Ratio Studiorum, é Santo Inácio, S. Francisco Xavier, Anchieta e a Companhia de Jesus que vão dizer ao mundo a palavra reveladora, que se consubstancia em catequese, apostolado, cultura e espírito.
\end{abstract}

Em Coimbra, ao se transpor a Porta Férrea, construída em 1634, tempo em que a Faculdade já estava ali instalada definitivamente, tem-se a sensação de deixar um mundo profano e entrar num mundo sagrado. Como noviços no internato, deixa-se o "mundo lá fora" para viver o "mundo aqui dentro", cheio de símbolos, conceitos, livros, verdades inquestionáveis, imutáveis, eternas. Uma capela, uma torre e um sino marcam as horas que não são mais "Kronos", são "Kairós", são de um tempo especial, sempre idêntico, porque é sempre eterno. Seus professores são pontífices, seus ensinamentos são dogmas, suas vestes são sacerdotais, suas cátedras são altares, suas licenças são bulas papais. Alunos são fiéis, são discípulos que seguem os mestres e bebem nas fontes de seus evangelhos e nos sermões da montanha das aulas magnas, segundo o método jesuítico do Ratio Studiorum, das salasauditório. De tempos em tempos, conferem suas sebentas, para devolver o que aprenderam; nas provas que lhes são aplicadas $^{12}$, para conferir se estão aptos para o reino dos escolhidos das vestes sacerdotais do mundo da justiça.

Transposta a Porta Férrea, vislumbra-se o grande Pátio da Faculdade, o Pátio das Escolas, o Olimpo do Saber. Antes de chegar à "Escada de Minerva", por aí peripatetavam os jurisconsultos do Reino, dizendo verdades em brocardos latinos, para julgar povos distantes, bem longe da Porta Férrea e da realidade desses sábios.

\footnotetext{
${ }^{12}$ Não pode passar despercebido este vocábulo, tão empregado, a lembrar que provas são como medicamentos amargos, ou injeções...
} 
Coimbra: à esquerda, claustro das aulas; ao centro, o Pátio das Escolas, torre, relógio e sino; à direita, a Porta Férrea, vista de fora

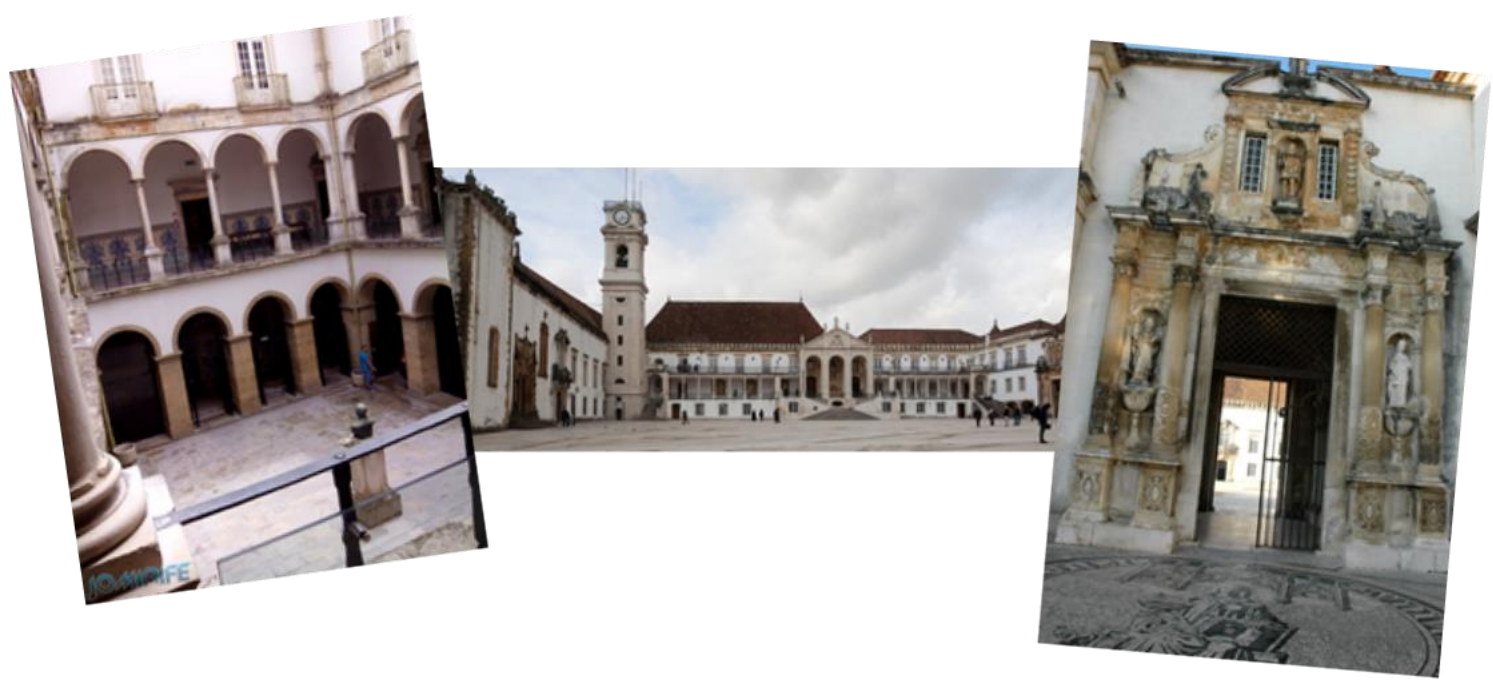

Ao entrar na Faculdade de Direito, ao redor desse claustro, construído certamente nas reformas posteriores, lá estão as salas de aula, onde, duplamente protegidos do burburinho do mundo e dos homens, os estudantes ouvem as aulas e as verdades jurídicas que lhes são ensinadas pelos mestres do Direito, segundo os métodos e os livros aprovados pelas autoridades, sempre sob os olhares vigilantes do reitor, que, de um corredor interno, tudo pode ver e ouvir pelas janelinhas.

\section{O claustro em Olinda, Recife e São Paulo}

Como visto acima, o curso de Direito de Olinda nasceu nos claustros do mosteiro de São Bento em 1827, e hoje se preserva nos claustros do majestoso prédio inaugurado em 1912, em Recife, tendo passado trinta anos pelo Colégio de Jesus, o colégio dos jesuítas. O curso de Direito de São Paulo ${ }^{13}$ iniciou-se nos claustros do convento franciscano, em 1827, e, mesmo com a reforma de 1930, em estilo neocolonial, preservou o claustro, nas suas Arcadas. "Especial destaque merece a Biblioteca, que, em 1825, já com acervo reunido de longa data pelos frades franciscanos, tornou-se a primeira biblioteca pública de São Paulo, antes mesmo

\footnotetext{
${ }^{13}$ Em cuja grade curricular estavam o Direito Natural, o Direito das Gentes, o Direito Eclesiástico. Começou se chamando Academia de Sciencias Juridicas, e Sociaes, S. Paulo. Disponível em <https://pt.wikipedia.org/wiki/Ensino_jur\%C3\%ADdico\#Cria\%C3\%A7\%C3\%A3o_dos_Cursos_Jur\%C3\%ADd icos_no_Brasil_no_in\%C3\%ADcio_do_S\%C3\%A9culo_XIX>.
} 
da inauguração da Faculdade"14. O Portal de Entrada sempre é o limiar que isola o "mundo lá fora" do "mundo aqui dentro", um mundo que muda, que se transforma, de um mundo que permanece. É sempre a antiga disputa entre Heráclito e Parmênides, ainda não totalmente resolvida.

As Arcadas - Claustro na Faculdade de Direito da USP/São Paulo.

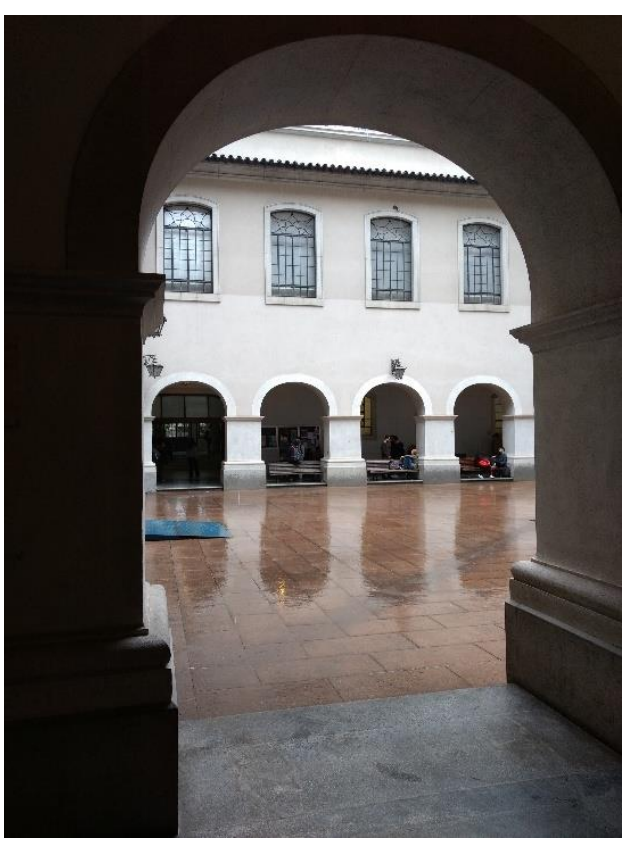

Fonte: Foto de autor: 15 agosto 2017 - 190 anos Cursos de Direito no Brasil

\section{Pombal expulsou os jesuítas, mas o jesuitismo triunfou}

Em 1599, os jesuítas aprovaram definitivamente o Ratio Studiorum, seu Método de Ensino, baseado nos ensinamentos da escolástica de Tomás de Aquino e na Bíblia. Sua influência foi duradoura em todo reino cristão ${ }^{15}$. O educador jesuíta, tornado hegemônico, está organicamente preso à metafisica tomista e aristotélica. O interesse da Companhia de Jesus é o estudo da teologia e das Escrituras, embora reconhecendo também que

para aprofundar nelas são necessários os estudos filosóficos e científicos (então chamados de Artes) [...]. A doutrina ensinada deve

\footnotetext{
${ }^{14}$ Disponível em <http://www.direito.usp.br/index_faculdade_01.php>.

${ }^{15}$ Em Portugal, o grande opositor do método jesuítico, foi Luís Antônio Verney (Lisboa, 1713 - Roma, 1792), padre oratoriano, autor de $O$ verdadeiro método de estudar (1746), que se contrapunha ao método escolástico dos jesuítas. Além dos jesuítas, sente-se, nas escolas, a influência do Guia das Escolas Cristãs, de João Batista de La Salle, publicado por volta de 1700.
} 
ser sólida e segura, qualidades reunidas pelo ensinamento de Santo Tomás de Aquino, em teologia, e pelo ensinamento de Aristóteles, corrigido pelo mesmo Santo Tomas de Aquino, em filosofia (CARDOSO, p. 59-60).

Por serem os responsáveis pelo Colégio das Artes, em Coimbra, que preparava para o ingresso na universidade, e pela Universidade de Évora, os jesuítas exerciam grande influência com o seu método. Diante disso, pode-se mesmo propor o seguinte: em 1759 os jesuítas, sob influência de Pombal, foram expulsos de todo o reino português. Mas o jesuitismo continuou vivo e mora um jesuitinha dentro de cada professor, tanto lá em Portugal, quanto cá no Brasil, principalmente nos cursos de Direito.

Em Évora, além de fotografar Tomás de Aquino que até hoje pontifica no hall de entrada da Universidade, foi possível admirar os púlpitos presentes em cada sala de aula e constatar "duas verdades" reveladas pelos anjos, nos azulejos, nas paredes das mesmas salas: “quaerit rerum essentias", e "semper abstracta".

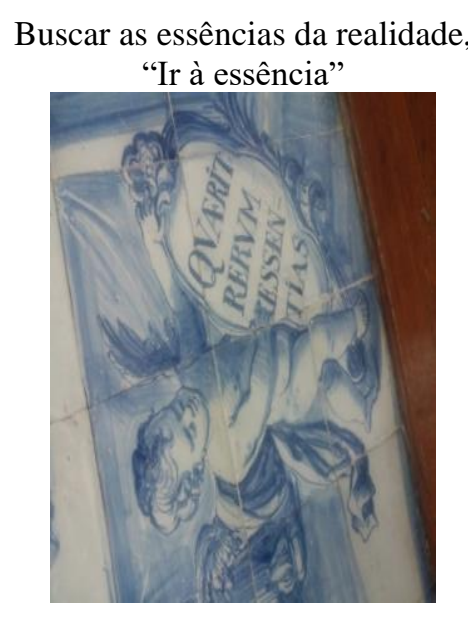

Sempre por abstração, Sempre abstratamente

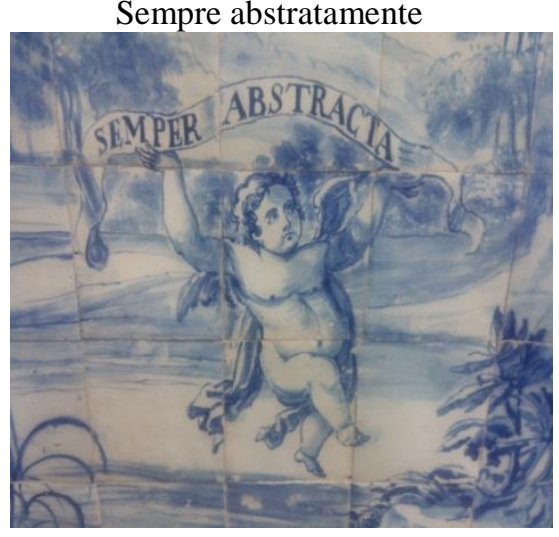


Ou seja, as coisas possuem uma essência. Esta não está no cotidiano, no aqui e no agora, mas num mundo imaterial. Será, quando muito, perceptível pelo espírito (outra expressão de imaterialidade).

\section{A metafísica do jesuíta}

O jesuitismo trouxe para o Brasil a visão de mundo da Igreja da Contra Reforma, com apoio na doutrina tomista, portanto na diretriz segundo a qual a salvação se obtém pela fé e pelas obras. Mas estas elevam o homem a um Deus etéreo, vago, que se satisfaz tanto com o serviço aos pobres quanto com o sacrifício destes, muitos deles escravizados. A servidão liberta, dirá Vieira: é uma dádiva aos brutos da África, antes sem Deus, agora purificados pela escravidão, servindo àqueles que são porta-vozes da fé cristã (VAINFAS, 2011). Nesse mundo, o direito que dá ao branco o poder de escravizar pagãos é o mesmo que legitima a ocupação da nova terra, já habitada, para glória do Senhor e bem do comércio.

Isto evidencia o que percebeu Sjaak de Boer (1998, p. 32), anotando que "a teologia sacramental do Ocidente origina-se principalmente da teoria". Ele acrescenta que "atos de amor e fé realizados pelo fiel constituem a Igreja [...]", para enfim concluir que, "no entanto, a abordagem teórica permanece vaga na concreta aplicação prática pastoral de sua sacramentologia no mundo e em sua apreciação de seu papel profético na transformação da sociedade" (ibidem).

Evidentemente não é por uma transformação social que atua o jesuíta no Brasil, nem esta é a finalidade do processo educacional que aqui inaugura e pratica por mais de duzentos anos. Seu objetivo é propagar a fé e incluir no seu projeto de salvação as populações que formam a identidade da nova colônia. Não se educa para ser cidadão, mas para ser cristão.

Essa fé no abstrato é melhor compreendida se, em contraponto, deitar-se o olhar sobre aquela fé pragmática na superação histórica da injustiça concreta, da qual hoje falam os teóricos da teologia da libertação, de larga penetração na América Latina. Aí a autenticidade dos valores cristãos está numa contradição insolúvel com a desigualdade e a pobreza, conforme se capta na fala de um trabalhador do campo salvadorenho, trazida por NelsonPallmeyer (1989, p. 15): 
que têm empregos são explorados diariamente nas fábricas e nas fazendas [...]. Não há trabalho. Isso traz mais fome, mais miséria. Estamos sem roupas, escolas ou empregos. E então nós protestamos. Mas [...] pedir pão é ser subversivo [...]. Ser cristão e exigir justiça é um crime (trad. livre).

É fácil ver a dualidade de pontos a partir dos quais se dá significado à fé cristã, do abstracionismo à prática historicizada. Daí o clamor de K. Rahner, citado pelo mesmo BOER, a postular que

\footnotetext{
A Igreja não deveria pregar apenas ideais abstratos. Já que a Igreja existe para realizar a salvação que ela mesma significa, ela deveria ser corajosa para exigir que seus membros servissem ao mundo de hoje e suas necessidades urgentes (idem, p. 29).
}

Mas inegavelmente é com aquela base teológica que mantém o jesuíta o monopólio da educação de crianças e jovens, em seus colégios, no Brasil nascente, por mais de duzentos anos, até a expulsão decretada pelo Marquês de Pombal. A esse tempo os alicerces do processo educacional já estavam lançados e sedimentados. Restaurada a legalidade da Companhia de Jesus, seus colégios e seus claustros darão lugar, a partir de 1827, às faculdades de direito. A matriz do que ali se ensinará segue sendo, em número e grau, aquela da teologia tomista, que já deitara profundas raízes na educação brasileira. Na sua busca pela essência das coisas e pela abstração, o ensino do Direito aproximar-se-á de Kant, no ponto em que admite uma presença da coisa em si, no mundo numênico, mas que não pode ser perfeitamente apreendida pelos sentidos. Isto é visivelmente metafísico, como metafísica é a principal matriz de conhecimento do jurista em geral ${ }^{16}$. Considerado que os destinatários desses cursos são os futuros dirigentes do país, como legisladores, juízes, administradores que também serão os futuros professores -, esse direito ensinado se reproduz e perpetua-se nos códigos e na sua interpretação.

\section{O método jesuíta dá as cartas no ensino jurídico}

A metodologia, assentada na escolástica e ainda inspirada no Ratio Studiorum, constituirá o par perfeito desse direito, ocupado da essência e da abstração, e assim contribuirá, por meio de seus processos classificatórios, sua metódica divisão de princípios e sub-princípios, suas categorias e nomenclaturação de elementos. Estes, cada vez mais

\footnotetext{
${ }^{16}$ Para Alysson Mascaro, o kantismo é, ainda hoje, a principal referência dos juristas brasileiros.
} 
distanciados da concretude, mostrar-se-ão incapazes de representar solução real para problemas causados pela multiplicidade de faces de que se compõe a realidade cotidiana, desigual para muitos e afinal incompreensível para o jurista assim ensinado.

Não por acaso alguns professores de direito, em geral das disciplinas fundamentais, insurgem-se contra o que veem como consequência de um processo que consideram irracional e incapaz de fugir do seu próprio eixo de rotação. Veja-se comentário bem humorado de José Manoel de Aguiar Barros (2002), advertindo que

o Direito não vai bem por aqui. Essa compulsão teórica, repetitiva,
classificatória, cada dia mais complexa e cerebrina por que passa o
direito, longe de exprimir a sua pujança, é sintoma de grave
enfermidade. Basta folhear um manual de direito processual para
qualquer pessoa de bom senso perguntar se com esse instrumental,
quase insano, é possível fazer justiça. O que deveria ser um meio
eficaz, a serviço do direito material, converteu-se num fim em si
mesmo, para alegria dos chicaneiros. Tornou-se impossível para um
profissional do Direito explicar para seus constituintes as peripécias
processuais.

O ensino nas faculdades, muitas vezes tangidas pela pressão em preparar o bacharel para o mercado, não foge da abstração e, não bastasse, prioriza a dogmática dos códigos, da lei posta e seus artigos, permanecendo numa interpretação gramatical e, quando muito, sistemática, do texto. O processo de ensino e aprendizagem volta-se à memorização dos conceitos - abstratos por definição - e da norma em vigor e da tendência jurisprudencial mais recente, em parte porque isto é o conteúdo dos exames pós-faculdade que serão experimentados pelos futuros bacharéis (GENTIL, 2011). Os cursinhos preparatórios acentuam o foco do estudo em conteúdos dessa espécie, o que universaliza o sentido do direito como abstração, divorciado, portanto, do concreto.

Conceitual e dogmático, o ensino jurídico vale-se de abstrações, não sendo raro deparar-se o professor com a dificuldade de explicar aos alunos como é que o direito, tão sisudo, admite algumas ficções (as ficções jurídicas, como aquela consistente em fazer de conta que o sujeito, culposamente embriagado, tem plena consciência do crime que está cometendo, ou a de que o réu citado por edital tem de fato ciência do pedido que contra ele se formula). 


\section{CONSIDERAÇÕES FINAIS}

O ensino do direito transplantado para o Brasil, via Olinda e São Paulo, e daí para o restante do território, parece trazer o estigma de uma escolástica ensinada nos claustros, de modo dogmático, difundida pelos jesuítas de Coimbra e Évora, sob as bênçãos dos anjinhos, a recordar que se deve buscar sempre as essências, por abstração de tudo o que é concreto, histórico, acidental. Assim, fechados no claustro dos pensamentos e dos conceitos, torna-se mais fácil ensinar, ou tentar ensinar, um direito positivo (verdadeira coleção de artigos, incisos e alíneas), distante da realidade concreta do mundo dos homens. São aulas apenas com livros que se assemelham às disputationes tomistas, cujas conclusões já são conhecidas antes dos debates, pois são decisões de autoridade.

Como não há formação pedagógica, com fundamentos históricos, epistemológicos, metodológicos e didáticos para os professores de direito, chega a ser viável a hipótese de que uns imitam os outros até chegarem aos seus primeiros mestres de Olinda e São Paulo, e... Coimbra. Afinal, não são muitas gerações. E as mesmas circunstâncias portuguesas estavam postas no Brasil: uma Casa Real e a influência da Igreja Católica. Aqui, ainda mais do que lá, pois, em Portugal, houve um decreto de Pedro IV, em 1834, de extinção de todas as ordens religiosas masculinas e a proibição de ingresso de noviças nas ordens femininas, até sua extinção. O rigor da extinção é reavivado em 8 de outubro de 1910, na implantação da república portuguesa.

Talvez, por isso, estudantes e professores não estranham que, ao entrarem num curso de Direito, passem a utilizar termos como "doutrina", "dogmática", "pontifica"; também se acostumam com vestes sacerdotais nos fóruns e nos rituais das tradicionais academias de direito. A imitação sem a reflexão, sem o estudo, não lhes deixa perceber que isso pode contaminar a evolução da teoria e da prática do direito e da justiça.

Uma philosophia, que foi ancilla theologiae escolastiquiae ${ }^{17}$, de caráter perene, imutável, não servirá, por exemplo, como fundamento para a teologia da libertação e, muito menos, para um direito contemporâneo, junto à realidade histórica e material, sempre em desenvolvimento.

As marcas do além-mar foram tão fortes que Olinda adotou por sua vocação ser a Coimbra brasileira.

\footnotetext{
${ }^{17}$ Filosofia, serva da teologia escolástica.
} 
De 1813 a 1822, anos finais do período colonial, matricularam-se em Coimbra 255 alunos nascidos no Brasil, e, desses, $78 \%$ nos cursos jurídicos, o que dá uma ideia da continuidade do espírito daquela universidade em Olinda e São Paulo. Não só os professores eram formados em Coimbra, como também muitos estudantes, que haviam iniciado o curso em Portugal, voltaram para terminar o seu curso no Brasil. Assim, vieram para Olinda e São Paulo os estatutos, os programas, os livros, os professores, os alunos e, obviamente, suas tradições e seus costumes. Assim, como dizem os historiadores, Olinda queria ser a Coimbra Brasileira.

Gilberto Freire (2007, p.59) diz:

O bispo Azeredo Coutinho foi talvez o primeiro brasileiro a sonhar para Olinda e para os seus montes um futuro tranquilo de cidade universitária que viesse consolar a antiga cidade de capitãesgenerais, de sua viuvez política. Ele fez do velho colégio dos jesuítas o esboço de uma universidade moderna, desenvolvendo ensino secundário em ensino superior ${ }^{18}$. Olinda seria uma espécie de Coimbra; e o Beberibe o seu Mondego.

Com a instalação do Curso Jurídico, fundado em 1827, no Convento de São Bento - que hoje se orgulha de ter abrigado escola tão ilustre nos seus primeiros anos - pareceu que Olinda se tornava definitivamente isto: um tranquilo burgo universitário e ao mesmo tempo eclesiástico.

Se em Coimbra havia um Colégio das Artes a preparar os alunos para a universidade, aqui havia um seminário, que fora erguido sobre o extinto Colégio de Jesus, dos mesmos jesuítas, outrora expulsos, lá e cá. Semelhanças e contradições acompanham as experiências além e aquém mar.

Há mais a buscar para apurar a impressão digital dos cursos de Direito no Brasil. Essas são as primeiras colheitas. A partir da presente pesquisa, há muitos passos a serem dados e que poderão contribuir com o diagnóstico mais preciso e, por consequência, para oferecer subsídios para a melhoria dos cursos.

Neste texto, os autores trazem esses frutos para o debate com os pares que estudam a educação jurídica no Brasil.

${ }^{18}$ Gilberto Freire refere-se à criação do Seminário de Olinda, em 1800, pelo Bispo Azeredo Coutinho. 


\section{REFERÊNCIAS}

A QUESTÃO ACADÊMICA EM 1871. s.a., s.d., s.e. (113p).

ALMEIDA JR, Antonio Ferreira de. Sob as arcadas: histórico da Faculdade de Direito de São Paulo. Brasília, MEC, 1965.

ALVES, Gilberto Luiz. Azeredo Coutinho. Recife: Massangana, 2010.

BARROS, José Manoel de Aguiar. Simplificar a linguagem jurídica. S. José do Rio Preto: Diário da Região, 24/dez./2002, p. 2.

BOER, Sjaak de. Por uma liturgia libertadora. São Paulo: Paulinas, 1998.

BASTOS, Aurélio Wander. Os cursos jurídicos e as elites políticas brasileiras: ensaios sobre a criação dos cursos jurídicos. Brasília, Câmara dos Deputados, 1978.

BASTOS, Aurélio Wander. O ensino jurídico no Brasil. Rio de Janeiro: Lumen Juris, 1998.

BEVILAQUA, Clóvis. História da Faculdade de Direito do Recife. 2.ed. Brasília: INL; Conselho Federal de Cultura, 1977.

BEVILAQUA, Clovis. Memória histórica: relativa ao anno de 1892, apresentada à Congregação da Faculdade de Direito do Recife.

BRAGA, THEOPHILO. História da Universidade de Coimbra nas suas relações com a instrução pública portugueza. Lisboa: Typographia da Academia Real das Sciencias,1892. (4 volumes).

CÂMARA, Phaelante da. Memória histórica da faculdade do Recife: anno de 1903. Recife: Imprensa Industrial, 1904. (119p.)

CARDOSO, Delmar. Jesuítas e filosofias. São Paulo, Loyola, 2012.

CARVALHO, Rómulo de. História do ensino em Portugal: desde a fundação da nacionalidade até ao fim do regime de Salazar-Caetano. $5^{\text {a }}$ ed. Lisboa. Fundação Calouste Gulbenkian, 2011.

CUNHA, Luiz Antônio. A universidade temporã. $2^{\mathrm{a}}$ ed. Rio de Janeiro, Francisco Alves, 1986. 
FRANCA, Leonel. O método pedagógico dos jesuítas: o Ratio Studiorum. Rio de Janeiro: Agir, 1952.

GENTIL, Plínio. Ensino jurídico, cidadania e fast food. In LIMA, Fernando Rister de Sousa. PORT, Otávio Henrique Martins, OLIVEIRA, Rafael Sérgio Lima de (coord.). Poder Judiciário, direitos sociais e racionalidade jurídica. São Paulo: Elsevier, 2011, pp. 71- 83.

LYRA FILHO, Roberto. O Direito que se ensina errado. Brasília: Centro Acadêmico da Universidade de Brasília, 1980.

MARCOS, Rui de Figueiredo; MATHIAS, Carlos Fernando; NORONHA, Ibsen. História do Direito brasileiro. Rio de Janeiro: Forense, 2015.

MARTINS, Ana Luiza e. Arcadas: história da Faculdade de Direito do Largo de São Francisco. São Paulo: Companhia Melhoramentos: Alternativa Serviços Programados, 1999. MASCARO, Alysson Leandro. Filosofia do Direito. São Paulo: Atlas, 2018.

MORAES, Geraldo Dutra de. A igreja e o colégio dos jesuítas de São Paulo. São Paulo: Prefeitura do Município, 1979.

NELSON-PALLMEYER, Jack. War against the poor: Low-intensity conflict and christian faith. New York: Orbis Books, 1990. Disponível em < http://media.sabda.org/alkitab2/Religion-Online.org\%20Books/Nelson-Pallmeyer\%2C\%20Jack\%20\%20War\%20Against\%20the\%20Poor\%20-\%20Low-intensit.pdf>.

TAGLIAVINI, João Virgílio. Aprender e ensinar Direito: para além do direito que se ensina errado. São Carlos: Edição do autor. 2013.

VEIGAS, Gláucio. História das ideias da Faculdade de Direito do Recife. Recife: Universitária UFPE, 1984. (8 volumes).

VAINFAS, Ronaldo. Antônio Vieira: jesuíta do rei. São Paulo: Companhia das Letras, 2011. WOLKMER, Antonio Carlos. História do Direito no Brasil. Rio de Janeiro: Forense, 1998. 